\title{
Maydole on Ontological Arguments
}

Maydole (2009) writes:

Ontological arguments are captivating. They convince some people but not others. Our purpose here was not to convince, but simply to show that some ontological arguments are sound, do not beg the question, and are insulated from extant parodies. Yet good logic does convince sometimes. Other times, something else is needed. (586)

On the way I understand these matters, any argument that is both sound and nonquestion-begging ought to be considered successful (and no argument that is subject to successful parody is sound). Be that as it may, what I propose to do here is to critically examine the ontological arguments of Maydole (2009). I claim that close examination reveals that these arguments are both question-begging and subject to successful parodies - and hence that nothing else is needed to permit non-believers to dismiss these arguments with good conscience.

\section{1. 'Anselm's Ontological Argument'}

Maydole 'reconstructs' Anselm's argument in the following way. We begin with definition of primitive vocabulary:

$\mathrm{Ux}$ : $\mathrm{x}$ is understood

Sx: the concept of $x$ exists in the understanding

Ex: $x$ exists in reality

Gxy: $x$ is greater than $y$

Fxy: $x$ refers to $y$

Dx: $\mathrm{x}$ is a definite description

d: '(lx) ᄏyGyx'

$\mathrm{g:}(\mathrm{ix}) \sim \exists \mathrm{yGyx}$

PX: $\mathrm{X}$ is a great-making property

(C): it is conceivable that

In standard form, the argument then runs as follows:

1. Dd\&Ud

2. Fdg

3. $(\forall \mathrm{x})(\forall \mathrm{y})((\mathrm{Dx} \& F x y \& U \mathrm{x}) \supset \mathrm{Sy})$

4. $(\forall x)(\forall Y)((P Y \& \sim Y x \&(Y x) \supset \bigodot \exists y G y x)$

5. $\mathrm{PE}$

6. $(\forall x)(S x \supset \odot E x)$

7. ( $\exists y G y g$

8. (Hence) Eg

It is easy to give a derivation of the conclusion from the premises. I think that Maydole makes slightly heavy weather of this. What we do is show that the hypothesis that $\sim$ Eg leads to a contradiction:

1. $\sim \mathrm{Eg}$

hypothesis for reductio 
2. Dd\&Ud

3. Fdg

4. $(\forall \mathrm{x})(\forall \mathrm{y})((\mathrm{Dx} \& \mathrm{Fxy} \& \mathrm{Ux}) \supset \mathrm{Sy})$

5. $(\forall x)(\forall Y)((P Y \& \sim Y x \&(Y x) \supset \bigcirc \exists y G y x)$

6. $\mathrm{PE}$

7. $(\forall x)(S x \supset \subset E x)$

8. (ㅋ $\exists$ yyg

9. Dd\&Fdg\&Ud

10. (Dd\&Fdg\&Ud) $\supset S g$

11. Sg

12. Sgつ@Eg

13. CEg

14. PE\& Eg\&@Eg

15. PE\& Eg\& $\subset E g \supset(\exists y G y g$

16. (C $\exists y G y g$

17. contradiction premise

premise

premise

premise

premise

premise

premise

2, 3 Conj

4, UI (twice)

9, $10 \mathrm{MP}$

7, UI

11, 12, MP

1, 6, 13 Conj

4, UI (twice)

14, $15 \mathrm{MP}$

8, 16

In words, Maydole gives the following standard form to the argument:

1. The definite description 'that than which it is not conceivable for something to be greater' is understood.

2. 'That than which it is not conceivable for something to be greater' refers to that than which it is not conceivable for something to be greater.

3. The concept of whatever a definite description that is understood refers to has existence in the understanding.

4. It is conceivable that something is greater than anything that lacks a greatmaking property that it conceivably has.

5. Existence in reality is a great making property.

6. Anything the concept of which has existence in the understanding conceivably has existence in reality.

7. It is not conceivable that something is greater than that than which it is not conceivable for something to be greater.

8. (Hence) That than which it is not conceivable for something to be greater exists in reality.

Maydole explains how he understands the distinction between existence in the understanding and existence in reality.

Notions, concepts, ideas, thoughts, beliefs, and so on are the kinds of things that do or might have existence in the understanding. Tables, persons, angels, numbers, forces, and so on, and God, are the kinds of things that do or might have existence in reality. We can identify the realm of things that have existence in the understanding with the totality of mental things that actually exist in minds; and we can identify the realm of things that have existence in reality with the totality of non-mental things that actually exist in the world. ... It is inconceivable that one and the same thing could have both existence in reality and existence in the understanding. (554-5) 
As Maydole acknowledges, this account of the distinction between existence in the understanding and existence in reality is multiply inconsistent with the text of Proslogion II. Maydole says: 'Either Anselm has been mistranslated or he misspoke.' (555) I don't think that we should accept this. Rather, we should suppose that Maydole is offering an argument that he was inspired to put forward by his reading of Proslogion II, even though it is absurd to suppose that this argument is actually developed in that text.

Maydole also tells us that 'referring singular terms and definite descriptions are free of existential import, and quantifiers range over possibilia' (555). That is: when we suppose that singular terms and definite descriptions are understood, we do not necessarily suppose that there are things that exist in reality to which those terms and descriptions refer-but we do necessarily suppose that there are things in the domains of some possible worlds to which those terms and descriptions refer.

It is worth reflecting on the consequences of this point. $g$ is defined to be the thing than which it is not conceivable that there is a greater thing. Given Premise 4, it follows from the definition that $g$ has all great making properties that it is conceivable that g possesses. While Maydole admits that he cannot give a theory of greatness and great making properties, it seems plausible to guess that Maydole supposes that it follows from the definition of $g$ and the correct account of greatness that perfect wisdom, perfect power, perfect goodness, completeness, existence in reality, sole creator of the universe ex nihilo, and necessary existence will all be on the list of great making properties that g possesses (since, in each case, he supposes that it is conceivable that g possesses that great making property).

Consider, now, the situation of a Fool who is committed to S5, and who is contemplating $g$. By the Fool's lights, can it be true both that he understands $g$ and that, if he understands $g$, then $g$ refers to a thing in the domain of at least one possible world? Plainly not, if we are supposing that $g$ is perfectly wise, perfectly powerful, perfectly good, necessarily existent and sole creator of the world ex nihilo-for the Fool denies that God exists and so, ipso facto, denies that it is even possible that there is a perfectly wise, perfectly powerful, perfectly good, necessarily existent, sole creator of the world ex nihilo.

The general points to be made are these. For an arbitrary description $d$, whether one should grant both (i) that one understands $d$, and (ii) that, if one understands $d$, then $d$ refers to a thing in the domain of at least one possible world, cannot be determined while there are features of the interpretation of $d$ that remain to be nailed down. Moreover, for an arbitrary description d, whether one should grant both (i) that one understands $d$, and (ii) that, if one understands $d$, then $d$ refers to a thing in the domain of at least one possible world, is not a straightforward matter if $d$ is taken to have modal content. Both of these points bear on Maydole's $g$. Unless we have a definite proposal about greatness in mind, it is not clear what we are being asked to countenance when we are asked to countenance 'the thing than which it is not conceivable that there is a greater thing'. And if we are being asked to suppose that necessary existence is a great making property, then no answer to the question whether $g$ refers can float free of considerations about what one supposes exists in reality. Consider 'the actually existent tallest Martian'. Perhaps there is some sense in which this expression is understood: at the very least, it is surely in no worse standing 
than $g$. But, if no Martians exist in reality, then it cannot be that there is a thing in the domain of at least one possible world that is picked out by this description. Or consider 'the necessarily existent, necessarily uncaused, necessarily initial, essentially natural state of the universe'. Again, it seems that there is some sense in which this description is understood; and, again, it seems obvious that it is in no worse standing than $g$. But, if our world did not begin with an uncaused initial natural state, then it cannot be that there is a thing in the domain of at least one possible world that is picked out by this description.

A natural conclusion to draw at this point is that the framework that Maydole erects for his Anselmian argument is ill-suited to the task of supporting a successful proof of the existence of God. This natural conclusion receives considerable further support when we turn our attention to parallel derivations based on descriptions such as 'that island than which it is not conceivable for some island to be greater' or 'that essentially supernaturally unaccompanied being than which it is not conceivable for some essentially supernaturally unaccompanied being to be greater'.

Maydole makes heavy weather of his discussion of parodies of Anselm's argument. The major problem is that he fails to consider the most obvious version of Gaunilo's perfect island objection. As before, we begin with definition of primitive vocabulary.

Ix: $\mathrm{x}$ is an island

$\mathrm{Ux}$ : $\mathrm{x}$ is understood

Sx: the concept of $x$ exists in the understanding

Ex: $x$ exists in reality

Gxy: $x$ is a greater island than $y$

Fxy: $x$ refers to $y$

Dx: $x$ is a definite description

j: '(1x)[Ix\& $\exists y(\operatorname{Iy} \& G y x)]$ '

i: (1x)[Ix\& $\exists y(\operatorname{Iy} \& G y x)]$

PX: $\mathrm{X}$ is a great-making property for islands

(C): It is conceivable that

In standard form, the argument then runs as follows:

1. $\mathrm{Dj} \& U \mathrm{Uj}$

2. Fji

3. $(\forall \mathrm{x})(\forall \mathrm{y})((\mathrm{Dx} \& F x y \& U \mathrm{x}) \supset \mathrm{Sy})$

4. $(\forall \mathrm{x})[\mathrm{Ix} \supset(\forall \mathrm{Y})((\mathrm{PY} \& \sim \mathrm{Yx} \&(\mathrm{Yx}) \supset \bigcirc \exists \mathrm{y}(\mathrm{Iy} \& \mathrm{Gyx})$

5. $\mathrm{PE}$

6. $(\forall x)(S x \supset \odot E x)$

7. $\bigcirc \exists y(I y \& G y i)$

8. (Hence) Ei

It is a trivial matter to show that the conclusion can be derived from the premises.

Certainly, it is no more difficult than in the case that is being parodied. We show that the hypothesis that $\sim$ Ei leads to contradiction. To simply the derivation, we leave out the derivation of Ii from the definition of i. Showing this is routine, but tiresome. 
2. Ii

3. $\mathrm{Dj} \& U \mathrm{Uj}$

4. Fji

5. $(\forall \mathrm{x})(\forall \mathrm{y})((\mathrm{Dx} \& \mathrm{Fxy} \& \mathrm{Ux}) \supset \mathrm{Sy})$

6. $(\forall x)[\operatorname{Ix} \supset(\forall Y)((P Y \& \sim Y x \& \subset Y x) \supset \odot \exists y(I y \& G y x))]$

7. $\mathrm{PE}$

8. $(\forall x)(S x \supset \odot E x)$

9. $\sim \exists \mathrm{x}(\mathrm{Ix} \& \mathrm{Gxi})$

10. Dd\&Fdg\&Ud

11. (Dd\&Fdg\&Ud) $\supset \mathrm{Si}$

12. $\mathrm{Si}$

13. $\mathrm{Si} \supset \subset \mathrm{Ei}$

14. CEi

15. $\mathrm{PE} \& \sim \mathrm{Ei} \& \subset \mathrm{Ei}$

$16 \mathrm{Ii} \supset(\forall \mathrm{Y})((\mathrm{PY} \& \sim \mathrm{Yi} \& @ \mathrm{Yi}) \supset @ \exists y(\mathrm{Iy} \& G y i))$

17. $(\forall Y)((P Y \& \sim Y i \& @ Y i) \supset @ \exists y(I y \& G y i))$

18. (PE\& Ei\&@Ei)つ@ $\exists y(I y \& G y i))$

19. $\bigcirc \exists y(I y \& G y i))$

18. contradiction from definition of $i$

premise

premise

premise

premise

premise

premise

premise

3, 4 Conj

5, UI (twice)

10, $11 \mathrm{MP}$

8, UI

12, 13, MP

$1,7,14$ Conj

6, UI

2, $16 \mathrm{MP}$

17, UI

15, $18 \mathrm{MP}$

9, 17

In words, we could give the following standard form to the argument:

1. The definite description 'that island than which it is not conceivable for some island to be greater' is understood.

2. 'That island than which it is not conceivable for some island to be greater' refers to that island than which it is not conceivable for some island to be greater.

3. The concept of whatever a definite description that is understood refers to has existence in the understanding.

4. It is conceivable that some island is greater than any island that lacks a greatmaking property for islands that it conceivably has.

5. Existence in reality is a great making property for islands.

6. Anything the concept of which has existence in the understanding conceivably has existence in reality.

7. It is not conceivable that some island is greater than that island than which it is not conceivable for some island to be greater.

8. (Hence) That island than which it is not conceivable for some island to be greater exists in reality.

Since the argument of the parody is plainly valid if the original argument is valid, all that remains is to consider the premises. As Maydole observes, what needs to be argued is that the premises of the parody are just as plausible (or implausible) as the premises of the original argument.

First, there is no evident reason why we should suppose that the description 'that than which it is not conceivable for something to be greater' is better understood than the description 'that island than which it is not conceivable for some island to be greater' Perhaps it might be said that all islands are equal: it makes no sense to suppose that one island is greater than another. However, even if this point were granted, it 
wouldn't matter: after all, for the purposes of the parody of the original argument, there is nothing special about islands. We can run exactly the same kind of argument in connection with cities, or horses, or poems, or human beings, or essentially supernaturally unaccompanied beings, or physically embodied creatures, or anything else for which we suppose that there is gradation on the scale of greater and lesser. The last case that I mentioned seems particularly apt. Anselm himself-along with any other medieval proponents of the great chain of being - clearly supposed that some physically embodied creatures are greater than others. But surely he would not have supposed that there is a physically embodied creature than which it is not conceivable for some physically embodied creature to be greater. Not only do physically embodied beings immeasurably greater than us exist out there in the stars, but those aliens are so great that they could not be conceivably greater-and we can demonstrate their existence and superiority purely a priori!

Second, there is no evident reason why we should suppose that the description 'that than which it is not conceivable for something to be greater' refers to that than which it is not conceivable for something to be greater, even though the description 'that island than which it is not conceivable for some island to be greater' fails to refer to that island than which it is not conceivable for some island to be greater. (Hereafter, for ease of exposition, I shall proceed as if it is agreed that some islands are greater than other islands. We have already seen that there is no risk involved in proceeding in this way.)

Third, there is no evident reason why we should suppose that it is conceivable that something is greater than anything that lacks a great-making property that it conceivably has, and yet not conceivable that some island is greater than any island that lacks a great-making property for islands that it conceivably has.

Fourth, there is no evident reason why we should suppose that existence is a great making property (for things in general) and yet existence is not a great making property for islands. How could that be? If, all else being equal, a thing that exists in reality is a greater thing than a merely possible thing, how could it not be that, all else being equal, an island that exists in reality is a greater island than a merely possible island?

Fifth, there is no evident reason why it is not conceivable that something is greater than that than which it is not conceivable for something to be greater, and yet it is conceivable that some island is greater than that island than which it is not conceivable for some island to be greater. Again, how could that be?

Since all of the remaining premises are in common between the two arguments, and since we have failed to find anything that speaks in favour of the original argument over the parody, and since the conclusion of the parody is absurd, we can quite properly conclude that the original argument is no good.

As I noted earlier, Maydole argues at some length that his version of Anselm's argument is not question begging. I think that he is wrong about this; moreover, I think that I can show that he is wrong about this. Consider the description 'that essentially supernaturally unaccompanied being than which it is not conceivable for some essentially supernaturally unaccompanied being to be greater'. (A being is 
'supernaturally unaccompanied' in world w iff there are no supernatural beings-no gods, no spooks, no spirits, etc.-in world w. A being is 'essentially supernaturally unaccompanied' iff there are no supernatural beings in any world in which that being exists.)

Consider the following argument (I omit symbolisation and derivation, since these are entirely straightforward):

1. The definite description 'that essentially supernaturally unaccompanied being than which it is not conceivable for some essentially supernaturally unaccompanied being to be greater' is understood.

2. 'That essentially supernaturally unaccompanied being than which it is not conceivable for some essentially supernaturally unaccompanied being to be greater' refers to that essentially supernaturally unaccompanied being than which it is not conceivable for some essentially supernaturally unaccompanied being to be greater.

3. The concept of whatever a definite description that is understood refers to has existence in the understanding.

4. It is conceivable that some essentially supernaturally unaccompanied being is greater than any essentially supernaturally unaccompanied being that lacks a great-making property for essentially supernaturally unaccompanied beings that it conceivably has.

5. Existence in reality is a great making property for essentially supernaturally unaccompanied beings.

6. Anything the concept of which has existence in the understanding conceivably has existence in reality.

7. It is not conceivable that some essentially supernaturally unaccompanied being is greater than that essentially supernaturally unaccompanied being than which it is not conceivable for some essentially supernaturally unaccompanied being to be greater.

8. (Hence) That essentially supernaturally unaccompanied being than which it is not conceivable for some essentially supernaturally unaccompanied being to be greater exists in reality.

There are naturalists—-myself among them—who hold that naturalism is necessary: there are no possible worlds in which there are supernatural entities. Such naturalists do not deny that it is conceivable that there are supernatural entities: but we deny that conceivability entails alethic or ontic possibility. (Conceivability is more properly considered to be something like doxastic possibility: it is conceivable that $\mathrm{p}$ iff it is alethically possible that there is a reasonable person who believes that p. Of course, reasonable people can have misleading evidence-e.g. false testimony from trusted authorities - that leads them to believe claims that are alethically impossible.)

Some theists - e.g. Maydole-suppose that there is a (supernatural) being which lacks spatiotemporal location but which causes the existence of the entire spatiotemporal realm. These theists suppose that this supernatural being exists of necessity, and that, necessarily, any spatiotemporal realm is created by this being.

Some naturalists — e.g. I - suppose that there are no supernatural beings: no causal agents that lack spatiotemporal location. Moreover, these naturalists suppose that this 
is a matter of necessity: there could not be causal agents that lack spatiotemporal location.

Maydole's version of 'Anselm's argument' and the above 'Naturalistic argument' have contradictory conclusions: it cannot be that they are both sound. However, it is obvious that any member of the class of naturalists described above will prefer the 'Naturalistic argument' to 'Anselm's argument'. For, while they may not believe that there is an essentially supernaturally unaccompanied being than which it is not conceivable for some essentially supernaturally unaccompanied being to be greater exists in reality, they may also be agnostic about the existence of such a beingwhereas they will positively disbelieve that there is a (supernatural) being than which it is not conceivable that a greater (supernatural) being exists in reality.

I take it that to insist - in the absence of any further argument - that 'Anselm's argument' is successful whereas the 'Naturalistic argument' is not, or to insist-in the absence of further argument' - that the 'Naturalistic argument' is successful whereas 'Anselm's argument' is not, would be to engage in blatantly question-begging behaviour. Moreover, and for similar reasons, I take it that to insist-in the absence of any further argument - that 'Anselm's argument' is not question-begging whereas the 'Naturalistic argument' is question-begging, or to insist-in the absence of further argument' - that the 'Naturalistic argument' is not question-begging whereas 'Anselm's argument' is question-begging, would equally be to engage in blatantly question-begging behaviour. But this latter is precisely what Maydole commits himself to when he claims that 'Anselm's argument' is sound and not questionbegging.

Maydole criticises Rowe for saying that 'the assumption that a greatest possible being possibly exists in reality is virtually equivalent to the proposition that it actually exists in reality' (562). Rowe's claim is made as a criticism of the following argument:

1. Some possible object exemplifies the concept of God.

2. No object that fails to exist in reality could exemplify the concept of God.

(Because God is defined as a being than which none greater is possible, and it is assumed that the property of existence in reality is great making.)

3. Every possible object either exists in reality or it does not.

4. Therefore God exemplifies the property of existence in reality.

I think that Maydole misses Rowe's point. Given that the argument 1, 2\&3 therefore 4 is valid, the argument not- $4,2 \& 3$, therefore not- 1 is also valid. If we grant $2 \& 3$ for the sake of further discussion, then we need to have a further reason to prefer one of these arguments to the other. In the absence of any further reason, it is simply questionbegging to assert that one of them is successful. Of course, as the pair of arguments makes clear, any reasonable person who accepts $2 \& 3$ and who supposes that some possible object exemplifies the concept of God will also suppose that God exemplifies the property of existence in reality; and any reasonable person who accepts $2 \& 3$ and who supposes that God does not exemplify the property of existence in reality will also suppose that there is no possible object that exemplifies the concept of God. But it is a commonplace that those who do not believe in a necessarily existent God do not suppose that such a God is even possible (at least given the unstated background acceptance of S5). Given S5 and 2\&3, the proposition that a greatest possible being 
possibly exists in reality swings rationally with the proposition that a greatest possible being actually exists in reality (this being what Rowe had in mind with his talk of 'virtual equivalence'); but that's not enough to justify the claim that the argument that Rowe criticises is a successful ontological argument.

\section{2. 'The Descartes-Leibniz Ontological Argument'}

According to Maydole, 'the Descartes-Leibniz ontological argument' runs as follows:

Lemma 1

1. If any two perfections are compatible, then all perfections are compatible.

2. If any two perfections are incompatible, then they are necessarily incompatible.

3. If any two perfections are necessarily incompatible, then it is either selfevident that they are incompatible or it can be demonstrated that they are incompatible.

4. It is not self-evident that any two perfections are incompatible.

5. If it can be demonstrated that any two perfections are incompatible, then either one is the negation of the other, or some part of the one is incompatible with the other.

6. If one perfection is the negation of the other, then one of them is not positive.

7. Perfections are simple positive qualities.

8. If some part of a perfection is incompatible with another perfection, then one of them is not simple

9. (Therefore) All perfections are compatible.

Lemma 2

1. All perfections are compatible.

2. Every essential property of a supremely perfect being is a perfection.

3. If something's essential properties are perfections and all perfections are compatible, then its essential properties are compatible.

4. If the essential properties of something are compatible, then it is possible that it exists.

5. (Therefore) It is possible that a supremely perfect being exists.

Theorem

1. For every $X$ and $Y$, if the property of being a $Y$ is contained in the concept or essence of being an $\mathrm{X}$, then necessarily everything that is an $\mathrm{X}$ is a $\mathrm{Y}$.

2. The property of necessarily existing if existing at all is contained in the concept or essence of a supremely perfect being.

3. It is possible that a supremely perfect being exists.

4. Necessarily, supremely perfect beings are necessarily supremely perfect.

5. (Therefore) A supremely perfect being exists.

Maydole claims that this argument is valid, non question-begging, not susceptible of parody, and not refuted by the Kantian objection that it treats existence as a real predicate. Moreover, he indicates that he believes that this argument is sound. 
I think that 'the Descartes-Leibniz ontological argument' is susceptible of parodythough not the kinds of parodies that Maydole considers—and that these parodies suffice to show that 'the Descartes-Leibniz ontological argument' is unsuccessful.

'The Descartes-Leibniz ontological argument' is implicitly committed to the claim that perfections form a totality (over which it is possible to quantify). For ease of exposition, I shall suppose that this totality is a set-but nothing would be lost if it were supposed that the totality is instead a proper class, or some other less set-like entity.

Call the set of perfections $P$. Suppose that $\left\{\mathrm{p}_{\mathrm{i}}\right\}$ is a set of logically independent members of $\mathrm{P}$ that collectively entail $\mathrm{P}$. Let $p_{1}$ be the property of existing necessarily if existing at all.

Let $\left\{\mathrm{q}_{\mathrm{i}}\right\}$ be a proper subset of $\left\{\mathrm{p}_{\mathrm{i}}\right\}$ that includes $\mathrm{p}_{1}$. Call the set entailed by $\left\{\mathrm{q}_{\mathrm{i}}\right\} Q$. Maydole tells us that perfections entail only perfections. If that is correct, then $\mathrm{Q}$ is a proper subset of $\mathrm{P}$.

Call the members of Q Q-perfections. Say that $\mathrm{x}$ is supremely Q-perfect iff $\mathrm{x}$ has all and only Q-perfections essentially.

We can then argue as follows:

\section{Lemma 1}

1. If any two Q-perfections are compatible, then all Q-perfections are compatible.

2. If any two Q-perfections are incompatible, then they are necessarily incompatible.

3. If any two Q-perfections are necessarily incompatible, then it is either selfevident that they are incompatible or it can be demonstrated that they are incompatible.

4. It is not self-evident that any two Q-perfections are incompatible.

5. If it can be demonstrated that any two Q-perfections are incompatible, then either one is the negation of the other, or some part of the one is incompatible with the other.

6. If one Q-perfection is the negation of the other, then one of them is not positive.

7. Q-Perfections are simple positive qualities.

8. If some part of a Q-perfection is incompatible with another Q-perfection, then one of them is not simple

9. (Therefore) All Q-perfections are compatible.

Lemma 2

1. All Q-perfections are compatible.

2. Every essential property of a supremely Q-perfect being is a Q-perfection.

3. If something's essential properties are Q-perfections and all Q-perfections are compatible, then its essential properties are compatible. 
4. If the essential properties of something are compatible, then it is possible that it exists.

5. (Therefore) It is possible that a supremely Q-perfect being exists.

\section{Theorem}

1. For every $X$ and $Y$, if the property of being a $Y$ is contained in the concept or essence of being an $\mathrm{X}$, then necessarily everything that is an $\mathrm{X}$ is a $\mathrm{Y}$.

2. The property of necessarily existing if existing at all is contained in the concept or essence of a supremely Q-perfect being.

3. It is possible that a supremely Q-perfect being exists.

4. Necessarily, supremely Q-perfect beings are necessarily supremely Q-perfect.

5. (Therefore) A supremely Q-perfect being exists.

It is, I think, obvious to inspection that this argument for the existence of a supremely Q-perfect being is valid just in case 'the Descartes-Leibniz ontological argument' for the existence of a supremely perfect being is valid. Moreover, it is also, I think, obvious to inspection, that there is no premise in the argument for the existence of a supremely Q-perfect being that is less acceptable than the corresponding premise in the argument for the existence of a supremely perfect being. (It is obvious that, if all perfections are compatible, then all Q-perfections are compatible, since all Qperfections are perfections. It follows immediately from the definition of supreme Qperfection that every essential property of a supremely Q-perfect being is a Qperfection. Premises 3 and 4 in Lemma 2 evidently stand or fall with the corresponding premises in 'the Descartes-Leibniz ontological argument'. And premises 2 and 4 in the Theorem evidently stand or fall with the corresponding premises in 'the Descartes-Leibniz ontological argument'.)

Suppose that you insist that 'the Descartes-Leibniz ontological argument' is successful. Suppose, further, that there are N+1 members of P. Then, by the above considerations, there are $2^{\mathrm{N}}$ distinct arguments, each of which is successful, and each of which demonstrates the existence of a distinct necessarily existent being that possesses essentially all and only some distinct subset of the properties possessed essentially by a supremely perfect being. If you suppose that, say, omnipotence, omniscience, perfect goodness, and perfect freedom are logically independent perfections, then this result is clearly heterodox (to say the least). But if you suppose that being the sole creator of everything else is also a perfection, then the result is simply logical incoherence.

Perhaps we might think to avoid these problems by insisting that there are only one or two logically distinct perfections. (Either there is just the perfection of existing necessarily if existing at all, or there is this perfection and one more that is logically distinct from it.) I'm inclined to think that this would be grasping at straws. At the very least, it would be passing strange to suppose that one needs to prove that perfections are compatible if one also supposes that there is only one perfection (and hardly less strange to suppose that something like the 'Leibniz' Lemma (Lemma 1) is needed if there are only two perfections)!

Perhaps we might think to avoid the problems raised two paragraphs back by insisting on further assumptions about perfections that play no role in 'the Descartes-Leibniz 
ontological argument', but that would undermine the construction of the argument from Q-perfections. Suppose, for example, that it is insisted that the property of having all perfections is itself a perfection. Since the property of having all perfections cannot be a Q-perfection, it is clear that some amendment to the above account will be required. However, I do not think that the required amendment is hard to find.

We start in the same fashion as before. Call the set of perfections $P$. Suppose that $\left\{p_{i}\right\}$ is a set of logically independent members of $\mathrm{P}$ that collectively entail $\mathrm{P}$. Let $p_{1}$ be the property of existing necessarily if existing at all.

However, at this point, we need to draw a distinction between two different kinds of properties that belong to P. On the one hand, there are basic properties: properties that are properly defined without making any mention of perfection. On the other hand, there are non-basic properties that are properly defined only in terms of perfectione.g. the property of possessing all of the perfections.

We now define $\left\{q_{i}\right\}$ in the following way. First, $\left\{q_{i}\right\}$ contains $p_{1}$. Second, $\left\{q_{i}\right\}$ contains a proper subset of the basic properties that are contained in $\left\{\mathrm{p}_{\mathrm{i}}\right\}$. Third, for each non-basic property in $\left\{\mathrm{p}_{\mathrm{i}}\right\},\left\{\mathrm{q}_{\mathrm{i}}\right\}$ contains a corresponding property with a corresponding proper definition in which 'perfection' is everywhere replaced with 'Qperfection'. (So, for example, $\left\{\mathrm{q}_{\mathrm{i}}\right\}$ contains the property of possessing all of the $Q$ perfections.) Given that there are $\mathrm{N}+1$ basic members of $\mathrm{P}$, there will be $2^{\mathrm{N}}$ distinct arguments, each of which purports to demonstrate the existence of a distinct necessarily existent being that possesses essentially all and only some distinct subset of the basic properties possessed essentially by a supremely perfect being.

Perhaps it might be said that there is something questionable about the impredicativity of the construction of the non-basic Q-perfections. But, of course, this impredicativity was introduced in the suggestion that the property of having all perfections is itself a perfection. If impredicativity is objectionable, then the original version of the parody stands; if impredicativity is not objectionable, then the revised version of the parody cannot be faulted on these grounds. And, I think, it is very hard to see any other grounds on which the revised version of the parody could be faulted.

\section{3. 'The Modal Perfection Argument'}

'The Modal Perfection Argument' may be presented in the following way (I have made a few minor alterations to the presentation that Maydole actually gives):

We begin with some definitions. We say that $\mathrm{x}$ is supreme just in case, necessarily, $x$ is greater than anything that is distinct from $x-\square \forall \mathrm{y}((\mathrm{x} \neq \mathrm{y}) \supset \mathrm{Gxy})$. We say that $\mathrm{F}$ is a perfection just in case, necessarily, $F$ is a property that it is better to have than not to have. We say that a property $\mathrm{F}$ entails a property $\mathrm{G}$ just in case, necessarily, anything that is $F$ is $G-\square \forall \mathrm{x}(\mathrm{Fx} \supset \mathrm{Gx})$. (We could also say that a set of properties $\Delta$ entails a property $\mathrm{F}$ just in case, necessarily, anything that possesses all of the properties in $\Delta$ is F. But we won't need this extension for our derivation.) 
We rely on the following Simple Lemma: If it is not possible that $\mathrm{F}$ is instantiatedi.e. if it is not possible that something is $\mathrm{F}$ - then $\mathrm{F}$ entails every property (including, in particular, $\sim \mathrm{F}$ ).

'The Modal Perfection Argument' has the following three premises:

1. A property is a perfection only if its negation is not a perfection.

2. Perfections entail only perfections.

3. The property of being supreme is a perfection.

We can formalise the derivation of the argument as follows:

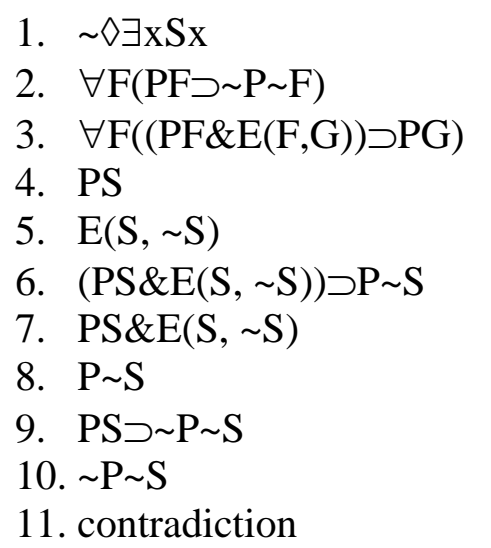

Assumption for reductio

Premise

Premise

Premise

From 1, Simple Lemma

From 3, UI

From 4, 5, \&I

From 6, 7, MP

From 2, UI

From 4, 9, MP

8, 10

1. $\diamond \exists x S x$

2. $\diamond \exists x S x \supset \exists x \diamond S x$

From preceding derivation

3. $\exists x \vee S x$

Barcan Formula

4. $\exists \mathrm{x} \diamond \square \forall \mathrm{y}((\mathrm{x} \neq \mathrm{y}) \supset \mathrm{Gxy})$

From 1, 2, MP

5. $\exists \mathrm{x} \square \forall \mathrm{y}((\mathrm{x} \neq \mathrm{y}) \supset \mathrm{Gxy})$

From 3, definition of $\mathrm{S}$

From 4, rules for S5

6. $\exists \mathrm{xSx}$

From 5, definition of $\mathrm{S}$

Maydole notes that the Barcan Formula is controversial. However, he goes on to claim that the argument is valid, possessed of plausible premises, resistant to 'sundry salient parodies' and not question-begging. In particular, Maydole says that 'we can easily show that an Oppy-Style parody based on the idea of being almost supreme does not refute the Modal Perfection Argument' (581).

I think that Maydole's 'Modal Perfection Argument' is susceptible to a Supreme Island parody. The simplest way to develop the argument is to interpret the above formalisation of the argument over the domain of possible islands, reading ' $G x y$ ' as ' $x$ is a greater island than $y$ ', ' $\mathrm{Sx}$ ' as 'necessarily, $\mathrm{x}$ is a greater island than any island distinct from $\mathrm{x}$ ' (' $\mathrm{x}$ is island-supreme'), and 'PF' as 'necessarily, $\mathrm{F}$ is a property that it is better for an island to have than not to have' (' $\mathrm{F}$ is an island-perfection').

The premises of the Supreme Island parody are then as follows:

1. A property is an island-perfection only if its negation is not an islandperfection.

2. Island-perfections entail only island-perfections. 
3. The property of being island-supreme is an island-perfection.

Following Maydole, we might think to justify these premises in the following terms:

1 is true because it is better for an island to have a property than not only if it is not better for that island to not have that property than not; 2 is true because it is always better for an island to have that which is a necessary condition for whatever it is better for that island to have than not; and 3 is true because it is reasonable to assume that an island is island-supreme iff it is necessarily greater than every other island solely by virtue of having some set of island-perfections, making the extension of the property of being island-supreme identical with the intersection of the extensions of those island-perfections. (Cf. 581.)

Clearly, we should not accept the conclusion of the Supreme Island parody. However, the notion of island-perfection seems innocuous. (As before, if you think that there are no island-perfections, then we can just change the subject, and talk about cities, or horses, or poems, or human beings, or essentially supernaturally unaccompanied beings, or physically embodied creatures, or anything else for which we suppose that there is gradation on the scale of better and worse, but for which we also suppose that it is evident that there is no supreme exemplar.) And if the notion of island-perfection is innocuous, then the first two premises seem unproblematic. So, I think, the problem must lie with the third premise: the claim that the property of being island-supreme is an island-perfection.

We might reflect in the following way. Given the definition of 'island-supremacy', if there is nothing that has that property, then it is impossible for there to be anything that has that property. But if it is impossible for anything to have that property, then that property entails all other properties. And yet our first two premises guarantee that no property that is an island-perfection entails all other properties. So whether or not we deem the third premise acceptable clearly depends upon whether or not we suppose that there is some island that possesses the property of being island-supreme. Given that we have good reason to suppose that there is no island that possesses the property of being island-supreme, we also have good reason to deny that third premise (its superficial attractiveness notwithstanding).

But now return to Maydole's Modal Perfection Argument. By the same kind of reasoning as that set out in the previous paragraph, whether or not we deem the third premise acceptable clearly depends upon whether or not we suppose that there is something that possesses the property of being supreme. If we properly take ourselves to have good reasons to deny that there is something that is supreme, then we shall also properly take ourselves to have good reasons to deny that the property of being supreme is a perfection. People who see things this way could argue as follows:

1. A property is a perfection only if its negation is not a perfection.

2. Perfections entail only perfections.

3. There is no supreme being.

4. (Hence) Supremacy is not a perfection.

Is there a non-question-begging reason to prefer Maydole’s Modal Perfection Argument to this alternative argument? I don't think so. Certainly, Maydole has not 
provided us with one. Look closely at his attempt to justify the claim that supremacy is a perfection. He says that 'it is reasonable to suppose that something is supreme iff it is necessarily greater than everything else solely by virtue of having some set of perfections, making the extension of the property of being supreme identical with the intersection of the extensions of those perfections'. While this might sound innocuous, the key point is that the way in which the word 'necessarily' is interpreted in Maydole's claim builds in the requirement that necessary existence is one of the requirements of supremacy. (Something is supreme only if, in each possible world, that thing is greater than every other thing in that world - hence, only if that thing exists in every possible world.) A genuinely innocuous interpretation of Maydole's claim would build in no more than a cross-world comparison: $x$ is supreme in world $w$ iff, for every possible world w', for every possible thing $x^{\prime}$, if $x$ in $w$ is distinct from $x$ ' in $w^{\prime}$, then $x$ in $w$ is greater than $x^{\prime}$ in $w^{\prime}$. But this innocuous claim is simply insufficient to yield Maydole's desired conclusion.

For all that Maydole says - in the article presently under examination and elsewhere-he has provided no non-question-begging reason to suppose that supremacy is a perfection. Indeed, for all that Maydole says - in the article presently under examination and elsewhere-he has provided no non-question-begging reason to prefer the hypothesis that supremacy is a perfection to the hypothesis that islandsupremacy is an island-perfection. He may think it obvious that it is not the case that island supremacy is an island-perfection; but many of us suppose that it is no less obvious that it is not the case that supremacy is a perfection (given that supremacy is taken to entail necessary existence).

\section{4. 'The Temporal-Contingency Argument'}

Maydole claims that 'the Temporal-Contingency Argument' is 'a quasi-ontological argument that is arguably sound' (586). In Maydole's eyes, 'There is ... no evidence to indicate that it begs the question. And it seems that it would be particularly resistant to being parodied, given its dependence on sundry logically contingent facts about a possible world, and the historical absence of any parodies against Third Way arguments.'

Maydole gives the following verbal formulation of the argument. We begin by numbering a list of propositions as follows:

1. Something presently exists.

2. Only finitely many things have existed to date.

3. Every temporally contingent being begins to exist at some time and ceases to exist at some time.

4. Everything that begins to exist at some time and ceases to exist at some time exists for a finite period of time.

5. If everything exists for only a finite period of time, and there have been only finitely many beings to date, then there was a time when nothing existed.

6. If there was a time when nothing existed, then nothing presently exists.

7. A being is temporally necessary iff it is not temporally contingent.

8. Everything has a sufficient reason for its existence.

9. Anything that has a sufficient reason for its existence also has a sufficient reason for its existence than is a sufficient reason for its own existence. 
10. No temporally contingent being is a sufficient reason for the existence of a temporally necessary being.

11. Every temporally necessary being that is a sufficient reason for its own existence is a being without any limitations.

12. A being without any limitations is necessarily greater than any other being.

13. It is not possible for anything to be greater than itself.

14. It is necessarily the case that 'greater than' is asymmetric.

We then argue:

1. Possibly $(1 \& 2 \& 3 \& 4 \& 5 \& 6 \& 7 \& 8 \& 9 \& 10 \& 11 \& 12 \& 13 \& 14)$

2. (Hence) There exists a supreme being.

Obviously, there are three parts to the argument. The first stage of the argument claims that the conjunction of 1-14 entails There exists a supreme being. The second stage of the argument consists in the observation that it then follows from Possibly (the conjunction of 1-14) that Possibly (There exists a supreme being). And the third stage of the argument consists in the observation that Possibly (There exists a supreme being) entails There exists a supreme being.

In order to think about this argument, let us contrast two different theories, which I shall call 'Theism' and 'Naturalism'. Of course, there are many theories that might properly be called 'Theism', and there are many theories that might properly be called 'Naturalism'. I don't pretend that the theories that are offer are the best deservers for these names; however, they are theories that are good deservers of these names.

Theism says: All alethically (ontically) possible worlds have an initial causal state that involves the same necessarily existent entity: God. It is controversial whether all possible worlds have the same initial causal state, because it is controversial whether there is variation in the properties possessed by God in that initial state across possible worlds. If all possible worlds have the same initial state, then, if there is more than one possible world, this is because chance plays a role in the evolution of state. If not all possible worlds have the same initial state, this is because there are bruteinexplicable-differences in the properties possessed by God in the initial state (e.g. brute differences in God's creative intentions, or God's preferences, or the like). According to Theism, God is the necessarily existent, essentially omnipotent, essentially omniscient, essentially perfectly good sole creator ex nihilo of the natural universe.

Naturalism says: All alethically (ontically) possible worlds have an initial causal state that involves the same necessarily existent natural entity: 'the initial singularity'. It is controversial whether all possible worlds have the same initial causal state, because it is controversial whether there is variation in the properties possessed by the initial singularity in that initial state across possible worlds. If all possible worlds have the same initial state, then, if there is more than one possible world, this is because chance plays a role in the evolution of state. If not all possible worlds have the same initial state, this is because there are brute-inexplicable-differences in the properties possessed by the initial singularity in the initial state (e.g. brute differences in the values of natural constants, or natural boundary conditions, or the like). According to 
Naturalism, the initial singularity is the necessarily existent, natural causal origin of the natural universe (and there is nothing supernatural in any possible world).

According to Naturalism, there are some propositions on Maydole's list that are not alethically possible. In particular, given that time commences with the initial state of the natural universe, it is not even possibly true that, if everything exists for only a finite period of time, and there have been only finitely many beings to date, then there was a time when nothing existed. Moreover, given the plausible claim that it is necessary that the physical universe is not a being that is without limitations, it is not even possibly true that every temporally necessary being that is a sufficient reason for its own existence is a being without any limitations. (For this second point, I assume that anything whose existence is alethically necessary is a sufficient reason for its own existence.) Given these points, it follows that, according to Naturalism, the premise of Maydole's argument is false.

I claim that the considerations just rehearsed establish that Maydole's argument is question-begging. It cannot be that both Theism and Naturalism are true. However, to insist that the premise of Maydole's argument is true is, ipso facto, to insist that Naturalism is false. But no successful argument for Theism (against Naturalism) requires the assumption that Naturalism is false: any argument that requires the assumption that Naturalism is false simply begs the question against Naturalism.

Of course, there are many naturalists who do not accept Naturalism. However, naturalists who do not accept Naturalism will reject other assumptions that are common to both Theism and Naturalism. Perhaps, for example, a naturalist might suppose that causal reality has a contingent origin. Or perhaps a naturalist might suppose that causal reality involves an infinite regress. Or perhaps a naturalist might be sceptical about causality, or modality, or sufficient reason. And so forth. The significant point upon which I want to insist here is just this: a naturalist who grants as much as possible to Theism can still reasonably prefer Naturalism to Theism-or, at any rate, Maydole's argument does nothing at all towards establishing that this is not the case.

Perhaps it is worth observing that it is highly contentious to describe 'the TemporalContingency Argument' as 'quasi-ontological'. The considerations that are relevant to its assessment seem to me to be vastly different from the considerations that are relevant to the assessment of 'Anselm's Ontological Argument', 'the Ontological Argument of Descartes and Leibniz', 'Ontological Arguments of the Twentieth Century', 'Gödel's Ontological Argument', and ‘the Modal Perfection Argument'. True enough, the final of the three stages of the argument - considered on its own-is a reasonably good deserver of the label 'ontological argument'. But it seems to me that the first two stages of the argument are something altogether different.

\section{Conclusion}

I agree with Maydole that ontological arguments are interesting. But that is pretty much where our agreement ends. I think that ontological arguments convince almost no one-and quite properly so: extant ontological arguments should not convince anyone. I have not yet seen an ontological argument that is (1) valid; (2) resistant to successful parody; and (3) non-question-begging. Certainly, the argument set out in 
Maydole (2009), while satisfying (1), all fail to satisfy both (2) and (3). Of course-as the preceding discussion shows - it is very important to match ontological arguments to appropriate parodies: there are different kinds of parodies that are appropriate to different kinds of ontological arguments. It is an interesting feature of the discussion in Maydole (2009) that — at least by my lights — in almost every case he fails to consider the kind of parody that is most threatening to whichever ontological argument is the immediate focus of his discussion.

\section{References}

Maydole (2009) 'The Ontological Argument' in W. Craig and J. Moreland (eds.) The Blackwell Companion to Natural Theology Malden, MA: Wiley-Blackwell, 553-87 